\title{
PODER REGULATÓRIO E PODER DE POLÍCIA: ADEQUAÇÃO DE CONCEITOS TRADICIONAIS AO (NOVO) CONTEXTO SOCIAL DEMOCRÁTICO
}

\author{
Américo Ribeiro Magro ; Fábio Ferreira Morong ${ }^{1}$ \\ ${ }^{1}$ Universidade Estadual de Londrina - UEL, Mestrado em Direito Negocial, Londrina, PR. ${ }^{2}$ Universidade do Oeste \\ Paulista - UNOESTE, Curso de Direito, Presidente Prudente, SP. E-mail: americomagro@hotmail.com
}

\begin{abstract}
RESUMO
O presente artigo pretende analisar conceitos relevantes do Direito Administrativo e Regulatório Brasileiros, isto é, regulação e poder de polícia, demonstrando, em especial, de que forma o primeiro forçou a transformação semântica do último num processo de retroalimentação que, ao fim e ao cabo, pretendeu sua adaptação ao vigente contexto social democrático. De início, delimitou as definições de regulação, poder regulatório e poder de polícia, para tanto se socorrendo de tradicional doutrina do Direito Administrativo. Após, definidas as terminologias analisadas, demonstrou a premente necessidade de adaptação das noções de polícia administrativa e poder de polícia à nova visão do Estado Democrático. Conclui-se, assim, que a atividade de polícia administrativa hoje se aproxima do conceito de regulação, de maneira que sua acepção tradicional não é mais suficiente à vigente complexidade socioeconômica. $O$ método aplicado foi o dedutivo e comparativo, baseado na interpretação da doutrina especializada no tema, tanto nacional como comparada.
\end{abstract}

Palavras-chave: Direito Administrativo; Regulação; Poder Regulatório; Poder de Polícia; Administração Pública.

\section{REGULATORY POWER AND POLICE POWER: ADEQUACY OF TRADITIONAL CONCEPTS TO THE (NEW) SOCIAL DEMOCRATIC CONTEX}

\begin{abstract}
This article, based on the authors' previous studies, seek to analyze relevant concepts of Brazilian Administrative and Regulatory Law, that is, regulation and police power, demonstrating, in particular, how the former forced the semantic transformation of the latter into a process that sought to adapt it to the current democratic social context. Initially, it delimited the definitions of regulation, regulatory power and police power under the traditional doctrine of Administrative Law. After defining the terminology analyzed, it demonstrated the urgent need to adapt the notions of administrative police and police power to the new vision of the Democratic State. It concluded, therefore, that the activity of administrative police is actually close to the modern concept of regulation, so that its traditional meaning is no longer sufficient to the current socioeconomic complexity. The article applies the deductive and comparative methods, based on the interpretation of the doctrine specialized on the subject, both national and foreign.

Keywords: Administrative Law; Regulation; Regulatory Power; Police Power; Public Administration.
\end{abstract}




\section{INTRODUÇÃO}

Após a nova afirmação da feição regulatória do estado, o conceito publicista de poder de polícia ("police power") e de polícia administrativa - de há muito incorporados à tradição do Direito Administrativo - merecem uma necessária revisão para que se adequem às novas circunstâncias socioeconômicas do Estado Social e Democrático de Direito.

Assim, num primeiro momento cuida de estabelecer, terminologicamente, os conceitos de regulação, poder regulatório e poder de polícia, ambos à luz da tradicional doutrina do Direito Administrativo. Por conseguinte, firmadas tais definições, buscará demonstrar a necessidade de revisão sobretudo da noção de poder de polícia, demonstrando como o advento do perfil regulatório do estado - sobretudo após a Constituição de 1988 - força sua adequação ao presente estágio de desenvolvimento social e econômico.

Isto consumado, traça uma relação de retroalimentação conceitual entre ambos, colacionando, para tanto, posicionamentos da literatura publicista nacional e comparada.

O presente artigo pretende demonstrar ser imprescindível a revisão e reformulação do conceito de poder de polícia, evidenciando como origem do perfil regulatório do estado, em especial depois da Constituição de 1988, que acaba por incentivar sua adequação à evolução geral da atualidade.

\section{METODOLOGIA}

O presente trabalho pauta-se pelos métodos histórico e comparativo no que tange à conferição entre a conceituação da doutrina alienígena com a pátria a respeito dos termos analisados e sua relação. Utiliza, ainda, o método dedutivo para sistematizar os dados coletados, a fim de cumprir o objetivo proposto.

\section{ORIGEM DO TERMO E APARENTES CONOTAÇÕES: REGULATION E REGULATOR}

Como cediço, a regulação "[...] engloba todas as formas de organização da atividade econômica através do Estado, seja a intervenção através da concessão de serviço público ou o exercício do poder de polícia" (SALOMÃO FILHO, 2001, p. 14).

Cuida-se, assim, de exemplo da intervenção indireta do estado, isto é, quando o ente estatal se limita a condicionar, a partir de fora, a atividade econômica privada, sem que assuma a posição de sujeito econômico ativo. Tal como explica Luís Cabral S. de Moncada (2003, p. 43):

$\mathrm{Na}$ intervenção indirecta o Estado nem sempre produz bens e serviços, orientando simplesmente a partir de fora a actividade dos sujeitos económicos, sejam eles privados ou públicos, de acordo com finalidades públicas ou simplesmente evitando que a actividade respectiva lese interesses socialmente relevantes. Trata-se da regulação.

Desta forma, qual aponta Marçal Justen Filho (2012, p. 642), "sob certo ângulo, a regulação consiste na utilização permanente, racional e intensificada das competências do poder de polícia".

Segundo Themístocles Brandão Cavalcanti (1960, p. 06/07), o poder de polícia "constitui um meio de assegurar os direitos individuais porventura ameaçados pelo exercício ilimitado, sem disciplina normativa, dos direitos individuais por parte de todos". Conforme resume o memorável publicista (CAVALCANTI, 1960, p. 07), trata-se de "[...] limitação à liberdade individual, mas tem por fim assegurar esta própria liberdade e os direitos essenciais ao homem".

Para Celso Antônio Bandeira de Mello (2010, p. 809), esta atividade estatal comporta dois sentidos, um amplo e outro restrito. Em sentido amplo, o poder de polícia abrange tanto atos do Legislativo quanto do Executivo, referindo-se, portanto, "ao complexo de medidas do Estado que delineia a esfera juridicamente tutelada da liberdade e propriedade dos cidadãos" (MELLO, 2010, p. 809) - por isso, argumenta o autor, "nos Estados Unidos, a voz police power reporta-se sobretudo as normas legislativas através das quais o Estado regula os direitos privados, 
constitucionalmente atribuídos aos cidadãos". Doutro modo, em sentido estrito, o poder de polícia, observa o publicista, relaciona-se unicamente

[...] com as intervenções, quer gerais ou abstratas, como os regulamentos, quer concretas e específicas (tais as autorizações, as licenças, as injunções), do Poder Executivo destinadas a alcançar o mesmo fim de prevenir e obstar ao desenvolvimento de atividades particulares contrastantes com os interesses sociais. Esta acepção mais limitada responde à noção de polícia administrativa (MELLO, 2010, p. 809).

O poder de polícia exercido pelo Estado pode incidir em duas áreas de atuação, administrativa e judicial. Segundo Maria Sylvia Zanella Di Pietro (2010, p. 118), "a principal diferença que se costuma apontar entre as duas está no caráter preventivo da polícia administrativa e no repressivo da polícia judiciária"; assim, "primeira terá por objetivo impedir as ações antissociais, e a segunda, punir os infratores da lei penal". Doutra forma, Álvaro Lazzarini (2008, p. 20/25 apud DI PIETRO, p. 118, 2010), sintetiza que

[...] a linha de diferenciação está na ocorrência ou não de ilícito penal. Com efeito, quando atua na área do lícito puramente administrativo (preventiva ou repressivamente), a polícia é administrativa. Quando o ilícito penal é praticado, é a polícia judiciária que age.

Não obstante as eventuais distinções, o que nos interessa, para os fins desta breve análise, é que a polícia judiciária é privativa de corporações especializadas (polícia civil e militar), ao passo que a polícia administrativa se reparte entre os diversos órgãos da Administração Pública, incluindo, além da própria polícia militar, "[...] os vários órgãos de fiscalização aos quais a lei atribua esse mister, como os que atuam nas áreas de saúde, educação, trabalho, previdência e assistência social" (DI PIETRO, 2010, p. 118).

Quanto à atuação, no exercício da atividade de polícia, pode a Administração agir de duas maneiras. Em primeiro lugar, pode editar atos normativos, que, segundo José dos Santos Carvalho Filho (2010, p. 91), "têm como característica o seu conteúdo genérico, abstrato e impessoal, qualificando-se, por conseguinte, como atos dotados de amplo círculo de abrangência". Nesse caso, "as restrições são perpetradas por meio de decretos, regulamentos, portarias, resoluções, instruções e outros de idêntico conteúdo" (CARVALHO FILHO, p. 91).

Além desses, a Administração, no exercício do police power, pode criar atos concretos, que são "preordenados a determinados indivíduos plenamente identificados, como são, por exemplo, os veiculados por atos discricionários, como a multa, e por atos de consentimento, como as licenças e autorizações" (idem).

Pois bem. Apesar de tradicionalmente enquadrado como função legítima do Estado, no esteio do que afirma Alexandre Santos de Aragão (2004, p. 33), temos que o poder de polícia é um dos temas que mais está a merecer atualização, considerando que "remonta ele a épocas em que a Administração Pública possuía uma competência 'natural' e genérica para conformar os direitos individuais a um metafísico 'interesse público'”. Segundo o autor (ARAGÃO, 2004, p. 33):

Em um Estado Democrático de Direito, a noção tem que, ao mesmo tempo, ser claramente limitada pelo conteúdo das leis, e ampliada para contemplar facetas regulatórias não existentes no Estado liberal-burguês que lhe deu origem. O próprio termo 'polícia administrativa' deve ser revisto, uma vez que o poder de polícia não é naturalmente inerente à Administração Pública de per se, mas a ele atribuído pela lei. Em última análise, portanto, o poder de polícia é do Legislador (art. 50, II, c.c. 37, caput, CF), que, através de conceitos jurídicos mais ou menos indeterminados, atribui o respectivo exercício e, geralmente, também a regulamentação, à Administração Pública.

No mesmo sentido, Agustín Gordillo (2010, p. 22) aponta que o poder de polícia: es una noción demasiado vieja a fines del siglo $\mathrm{XX}$, uncida al carro de las tradiciones autoritarias de ese mismo siglo, de que tanto nos cuesta desprendernos. No tiene cabida 
en el siglo XXI. Y está finalmente cediendo su lugar a uma proposición que al menos se presenta a sí misma como eje de debate, antes que como postulación de poder ${ }^{1}$.

E conclui o ilustre autor (2010, p. 22):

[...] la "noción" de policía es ambigua, confusa y además peligrosa por el uso que históricamente se ha hecho de ella. Si algún argumento hubiera en derecho para sostenerla podría correrse el riesgo de hacerlo. Sin embargo, no lo hay y sólo por algún extraño fenómeno de resistencia al cambio, temor a lo nuevo, comodidad, apego a lo antiguo, empatía con el poder o la razón que fuere, se mantenga en vigor lo que ya ha sido y puede volver a ser, sepultura de la libertad. Sostener esta noción es negar la finalidad misma del derecho administrativo; es en definitiva deliberadamente preferir el poder y no la libertad; la autoridad y no los derechos ${ }^{2}$.

Tais ajustes necessários ao conceito do poder de polícia face às novas perspectivas do Estado Democrático de Direito, somados à multiplicidade de funções assumidas por este novo modelo político (de perfil regulador da economia), fazem crer em alguns autores que se está diante de uma "deformação do conceito tradicional de polícia administrativa", que tenha por objeto a intervenção no domínio econômico, consistente em "toda uma variada gama de técnicas restritivas e moduladoras da liberdade de indústria e comércio por meio das quais o Estado desenvolve um importante meio de atuação" (CHIRILLO, 2003, p. 461 apud ARAGÃO, 2004, p. 35).

Segundo Alexandre Santos de Aragão (2004, p. 34),

a perplexidade desses autores com o 'novo' poder de polícia sobre a economia, faz com que afirmem que esta atividade, fundada em um interesse público para assegurar a 'ordem pública econômica', que apresenta uma importante semelhança com a atividade de polícia, deva ser denominada de regulação das atividades econômicas.

Em vista disso, Gaspar Ariño Ortiz (1993, p. 50) estabelece a seguinte distinção entre polícia econômica e regulação econômica: a polícia econômica tem caráter externo, obstando que a atividade econômica prejudique o meio ambiente, a saúde pública, os padrões urbanísticos, a segurança, etc., ao passo que a regulação econômica centra-se, fundamentalmente, na entrada e saída da atividade e afeta as condições econômicas em que a atividade se desenvolve: o quantum de produção, as zonas ou mercados em que atua cada empresa, os preços ou retribuições que recebem em decorrência da atividade e o negócio mesmo em que consiste a atividade.

Em meios nacionais, uma das mais relevantes (e pioneiras) revisões que o conceito de poder de polícia recebeu se credita a Carlos Ari Sundfeld, por ocasião de sua notável obra "Direito Administrativo Ordenador". Nela, como o próprio título faz indicar, Sundfeld substitui a acepção do poder de polícia pela noção de Direito Administrativo Ordenador, em oposição ao Direito Administrativo Prestacional, e que corresponderia à "[...] parcela da função administrativa desenvolvida com o uso do poder de autoridade, para disciplinar, nos termos e para os fins da lei, os comportamentos dos particulares no campo que lhe é próprio" (SUNDFELD, 2000, p. 32).

A despeito disso, para Alexandre Santos de Aragão (2004, p. 35), regulação parece assumir um sentido mais amplo do que a administração ordenadora e o poder de polícia. De fato, segundo o autor (2004, p. 35),

[...] a doutrina do Direito Público Econômico faz uso deste termo para tratar da mecânica estatal de ordenação das atividades econômicas em geral, incluindo, portanto, os serviços públicos e as atividades econômicas em sentido estrito. Sendo assim, o Estado

\footnotetext{
1 “É noção muito antiga já no final do século XX, unida ao movimento das tradições autoritárias do mesmo século, do qual é tão difícil nos desprendermos. Não tem lugar no século XXI. E finalmente está dando lugar a uma proposição que pelo menos se apresenta como o eixo do debate, e não como uma postulação do poder" (Tradução livre).

2 “A 'noção' de polícia é ambígua, confusa e também perigosa por causa do uso que historicamente foi feito dela. Se qualquer argumento tivesse o direito de sustentá-lo, poderia haver um risco de fazê-lo. No entanto, não há, e somente por algum estranho fenômeno de resistência à mudança, medo do novo, conforto, apego ao antigo, empatia com poder ou qualquer outra razão poderia ser mantido em vigor o que já foi, e poderia voltar a ser, a sepultura da liberdade. Sustentar essa noção é negar o próprio propósito do Direito Administrativo; em última análise, é deliberadamente preferir poder e não liberdade; a autoridade e não os direitos" (tradução livre).
} 
desempenha a regulação tanto quando tem vínculo genérico com o administrado (livre iniciativa da atividade econômica em sentido estrito) quanto no caso de possuir vínculo específico (serviços públicos prestados mediante concessão ou permissão).

De qualquer modo, com a devida vênia aos posicionamentos diversos, forçoso entender que a delimitação da diferenciação entre poder de polícia e a regulação (ou poder regulatório, se assim se entender), dependerá do ponto de vista do operador: partindo-se de um conceito tradicional de "police power", oitocentista, restrito à fiscalização da atividade econômica para que esta não causa prejuízos à coletividade, temos que o âmbito conceitual da regulação será mais amplo do que o do poder de polícia (ARAGÃO, 2004, p. 35).

Doutro modo, caso endossemos um conceito de poder de polícia mais próximo dos padrões do Estado Democrático de Direito, da atual conjuntura socioeconômica do modelo regulatório e que seja praticado de acordo o dever de compatibilizar, na medida do possível, as atividades privadas ao interesse coletivo, temos que tal (o conceito de poder de polícia) se aproxima do conceito de regulação, "[...] apesar de não alcançá-lo in totum por não abranger a regulação dos serviços públicos e outros aspectos a ela inerentes, tais como o da composição dos conflitos" (ARAGÃO, 2004, p. 36).

De forma diversa, Marçal Justen Filho (2012, p. 642) aponta que "a ampliação da complexidade socioeconômica conduziu à necessidade de ampliação do conceito de intervenção estatal" que constitui objeto do poder de polícia. Assim, para o autor (2012, p. 642), "a regulação é um estágio posterior nessa evolução, em que o Estado restringe a autonomia dos particulares, visando a constrangê-los ou a induzi-los a produzir as condutas reputadas como socialmente úteis ou indispensáveis".

Seja por uma outra via, é patente que tais conceitos merecem adequada transmutação para que afinal se adequem ao presente estágio de desenvolvimento social do direito, sobretudo impulsionado pelo advento da Carta de 1988 e pela afirmação do vigente Estado Democrático.

\section{CONCLUSÃO}

A par da presente pesquisa, pretendeu-se demonstrar que o desenvolvimento da complexidade socioeconômica por si forçou ao estado assumir outras feições além de suas competências soberanas tradicionais. Tal transformação ocasionou uma maior delimitação das formas de atuação do ente estatal na economia, sobretudo com o advento dos mecanismos de intervenção indireta, cuja manifestação importante é da regulação e do seu "novo" poder regulatório.

A concepção desta nova forma de intervenção indireta, a regulação, forçou, por retroalimentação, que a noção de poder de polícia - especificamente em seu sentido estrito, de adequação da atividade privada ao interesse público - sofresse uma transformação para, distanciando-se de sua raiz tradicional publicista, adequar-se ao novo, e vigente, contexto do Estado Social e Democrático de Direito.

Consigna, a este propósito, que procurou não ingressar no mérito das espécies de poder de polícia - a exemplo da tipologia de Hely Lopes Meirelles, que cogita, por exemplo, de um poder de polícia sanitário, como o exercido pelas competências atribuídas à Agência Nacional de Vigilância Sanitária (Anvisa).

De todo modo, pontua-se que a transformação conceitual analisada é necessária independentemente do perfil do poder político em exercício, eis que, ceda à matriz liberal ou intervencionista, o Estado sempre exercerá alguma forma e grau de atividade interventiva notadamente no caso pátrio, em que o ente estatal ainda persiste como relevante agente econômico. 


\section{REFERÊNCIAS}

ARAGÃO, Alexandre Santos de. Agências reguladoras e a evolução do direito administrativo econômico. 2. ed. Rio de Janeiro: Forense, 2004.

CARVALHO FILHO, José dos Santos. Manual de direito administrativo. 23. ed., rev., ampl. e atual. Rio de Janeiro: Lumen Juris, 2010.

CAVALCANTI, Themistócles Brandão. Tratado de direito administrativo. Vol. 3. 4. ed. Rio de Janeiro: Freitas Bastos, 1960.

CHIRILLO, Eduardo J. Rodríguez. Privatización de la Empresa Pública y Post Privatización. Buenos Aires: Ed. Abeledo-Perrot, 2003.

DI PIETRO, Maria Sylvia Zanella. Direito administrativo. 22. ed. São Paulo: Atlas, 2009.

GORDILLO, Agustín. Tratado de derecho administrativo: el acto administrativo. Tomo 3. 10 ed. Buenos Aires: Fund. de Derecho Adminstrativo, 2010.

JUSTEN FILHO, Marçal. Curso de direito administrativo. São Paulo: Saraiva, 2012.

MELLO, Celso Antônio Bandeira de. Curso de direito administrativo. 27. ed., rev. e atual. São Paulo: Malheiros, 2010.

MONCADA, Luís S. Cabral de. Direito económico. 4. ed., rev. e atual. Coimbra: Coimbra Ed., 2003.

ORTIZ, Gaspar Ariño. Economia y Estado: crisis y reforma del sector público. Madrid: Marcial Pons, 1993.

SUNDFELD, Carlos Ari. Direito Administrativo Ordenador. São Paulo: Malheiros, 2000. 